\title{
Therapeutic effects of amniotic fluid-derived mesenchymal stromal cells on lung injury in rats with emphysema
}

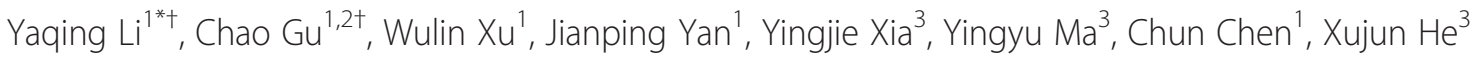 \\ and Houquan $\mathrm{TaO}^{3}$
}

\begin{abstract}
Background: In chronic obstructive pulmonary disease (COPD), two major pathological changes that occur are the loss of alveolar structure and airspace enlargement. To treat COPD, it is crucial to repair damaged lung tissue and regenerate the lost alveoli. Type II alveolar epithelial cells (AECII) play a vital role in maintaining lung tissue repair, and amniotic fluid-derived mesenchymal stromal cells (AFMSCS) possess the characteristics of regular mesenchymal stromal cells. However, it remains untested whether transplantation of rat AFMSCS (rAFMSCs) might alleviate lung injury caused by emphysema by increasing the expression of surfactant protein (SP)A and SPC and inhibiting AECII apoptosis.

Methods: We analyzed the phenotypic characteristics, differentiation potential, and karyotype of rAFMSCs, which were isolated from pregnant Sprague-Dawley rats. Moreover, we examined the lung morphology and the expression levels of SPA and SPC in rats with emphysema after cigarette-smoke exposure and intratracheal lipopolysaccharide instillation and rAFMSC transplantation. The ability of rAFMSCs to differentiate was measured, and the apoptosis of AECll was evaluated.
\end{abstract}

Results: In rAFMSCs, the surface antigens CD29, CD44, CD73, CD90, CD105, and CD166 were expressed, but CD14, CD19, CD34, and CD45 were not detected; rAFMSCs also strongly expressed the mRNA of octamer-binding transcription factor 4, and the cells could be induced to differentiate into adipocytes and osteocytes. Furthermore, rAFMSC treatment up-regulated the levels of SPA, SPC, and thyroid transcription factor 1 and inhibited AECII apoptosis, and rAFMSCs appeared to be capable of differentiating into AECIl-like cells. Lung injury caused by emphysema was alleviated after rAFMSC treatment.

Conclusions: rAFMSCs might differentiate into AECII-like cells or induce local regeneration of the lung alveolar epithelium in vivo after transplantation and thus could be used in COPD treatment and lung regenerative therapy.

Keywords: Mesenchymal stromal cells, Amniotic fluid, Pneumocytes, Chronic obstructive pulmonary disease, Pulmonary emphysema

\section{Introduction}

Chronic obstructive pulmonary disease (COPD), which is considered to become the third-leading cause of death worldwide by 2020 , is currently recognized as a major global public health challenge. In COPD, the major mechanisms underlying chronic airflow limitation are

\footnotetext{
*Correspondence: lidoctor03@126.com

${ }^{\dagger}$ Equal contributors

'Department of Respiratory Medicine, Zhejiang Provincial People's Hospital, No. 158, Shangtang Road, Hangzhou, Zhejiang 310014, P.R. China Full list of author information is available at the end of the article
}

the perpetual loss of alveolar structure, which causes airspace enlargement, and the destruction of the lung parenchyma and the loss of elastic recoil [1]. The loss of alveolar structure and airspace enlargement are key pathological changes in COPD [2], as a result of the development and progression of pulmonary airflow limitation. In the progression of COPD, a critical role is played by the apoptosis of lung epithelial cells, which results in the destruction of the alveolar structure and in emphysema [3]. However, no effective treatment is available for preventing the decline of pulmonary function in patients with COPD. Therefore, 
the key to treating COPD is to repair damaged lung tissue and regenerate the lost alveoli.

In mammals, the alveolar epithelium is composed of type I alveolar epithelial cells (AECI) and type II alveolar epithelial cells (AECII). AECII are multifunctional secretory cells that are characterized by the presence of morphological lamellar bodies containing pulmonary surfactant proteins (SPs) and lipids. AECII can differentiate into AECI in the alveoli and proliferate to maintain their own number through mitosis [4]. As progenitors of AECI, AECII play vital roles in synthesizing and secreting lung surfactants, which include SPA, SPB, SPC, and SPD, reducing the surface tension of the alveoli, maintaining normal alveolar homeostasis and gas exchange, and improving lung tissue repair $[4,5]$.

Stem cell therapy has attracted considerable attention because of its potential for application in the treatment of COPD, pulmonary fibrosis, cystic fibrosis, and other respiratory diseases [6-8]. By serving as the source of new epithelial cell populations, the resident lung progenitor cells can repair the injured lung epithelium in vivo [9]. However, the regenerative capacity of the lung is widely recognized to decline with aging and as a result of extensive damage such as that in COPD; this extensive lung damage might not be repaired appropriately by the endogenous stem niches [10]. Moreover, no evidence is available to suggest that endogenous stem cells can function in alleviating chronic lung disease. However, over the past decade, major breakthroughs in the research on exogenous stem cells have brought new hope for the treatment of COPD. Currently, the exogenous stem cells used mainly include embryonic stem cells (ESCs), bone marrow-derived mesenchymal stromal cells (BMMSCs), and amniotic fluidderived stromal cells (AFSCs). ESCs are pluripotent stem cells that can be induced to differentiate into various types of cells and ESCs exhibit substantial capacity to proliferate indefinitely $[11,12]$. For example, ESCs can be induced to differentiate into AECII both in vitro and in vivo [13,14]. Similarly, BMMSCs alleviate the destruction of lung tissues by also differentiating into AECII in vivo $[15,16]$. However, the challenges involved in acquiring large numbers of BMMSCs from the bone marrow and the low efficiency of their differentiation have restricted research on the use of BMMSCs in regenerative medicine.

Another potential source of cells for lung regeneration in vivo are mesenchymal stromal cells (MSCs), which include BMMSCs, amniotic fluid-derived MSCs (AFMSCs), adipose-derived MSCs, and cord blood-derived MSCs; this is because MSCs exhibit the capacity to differentiate into alveolar epithelial cells [17-19]. MSCs have previously been shown to exert beneficial effects on various animal models of respiratory diseases because the cells possess immunomodulatory and anti-inflammatory abilities; the effects of MSCs have been demonstrated in diseases such as COPD [20,21] and asthma [22,23] and in lung fibrosis caused by interstitial lung disease [24] and lung injury caused by acute respiratory distress syndrome [25]. Huh et al. [21] reported that MSC-based cell therapy repaired cigarette smoke-induced emphysema in rats after the injection of cells for 2 months. Recently, a placebocontrolled, randomized trial of MSC treatment in patients with moderate-to-severe COPD was published; after the infusion of allogeneic MSCs in COPD patients, no deaths, toxicity, or serious adverse reactions related to the MSC therapy occurred, but the circulating levels of C-reactive protein in the patients were markedly decreased [26].

De Coppi et al. [27] reported for the first time that AFSCs can be obtained from discarded amniocentesis specimens and that these cells possess the potential to differentiate widely into neural cells, adipocytes, osteocytes, endotheliocytes, hepatocytes, and cardiomyocytes [28-30]. Thus, AFSCs are recognized as new multipotent stem cells that can be used in regenerative medicine without raising concerns regarding ethical problems or tumorigenesis [31,32]. Furthermore, Carraro et al. [33] showed that AFSCs integrated into the embryonic lung tissues of mice, differentiated into lung epithelial cells, and expressed thyroid transcription factor 1 (TTF1) after lung injury in vivo. AFMSCs exhibit the characteristics of MSCs in vitro, by expressing molecules such as CD73, CD90, CD105, and CD166 $[34,35]$. AFMSCs were previously shown to be capable of differentiating into AECII-like cells in vitro, which indicated that AFMSCs can potentially be used in lung-tissue regenerative therapy [35]. Moreover, rat AFMSCs (rAFMSCs) were shown to secrete neurotrophic factors and thereby promote the regeneration of the injured sciatic nerve [36] and to over-express the interleukin-1 receptor antagonist and thus improve hepatic function in vivo in rats with fulminant hepatic failure [37]. However, whether rAFMSCs can exert therapeutic effects on lung injury caused by emphysema is unknown. In this study, we transplanted rAFMSCs into rats with emphysema and then investigated whether the rAFMSCs integrated into lung tissue, expressed AECII-specific markers, inhibited AECII apoptosis, and alleviated lung injury caused by emphysema.

\section{Materials and methods}

Animals

We purchased 15 pregnant Sprague-Dawley rats (body weight, $300 \sim 350 \mathrm{~g}$, at 12-14 days of pregnancy) and 60 female Sprague-Dawley rats (body weight, 180-200 g) from Shanghai SLAC Laboratory Animal Co., Ltd (Shanghai, China). All animal protocols were approved by the Ethics Committee of Zhejiang Provincial People's Hospital.

\section{Isolation and culture of rAFMSCs}

We isolated rAFMSCs from pregnant Sprague-Dawley rats as described by Pan et al. [36]. The rats were deeply 
anesthetized using $10.0 \%$ chloral hydrate, and then 15 independent amniotic fluid samples $(2 \mathrm{~mL}$ each) were harvested from fetal male rats by using 22-gauge needles. Each sample was filtered through a 200-mesh filter and centrifuged for $10 \mathrm{~min}$ at $1,500 \mathrm{rpm}$. The cells were resuspended in low-glucose Dulbecco's modified Eagle's medium (DMEM; Gibco, Carlsbad, CA, USA) supplemented with $20 \%$ fetal bovine serum (FBS; HyClone, Logan, UT, USA) and $4 \mathrm{ng} / \mathrm{mL}$ basic fibroblast growth factor (bFGF; Sigma, St. Louis, MO, USA), and then maintained in 6-well plates and grown in a humidified incubator at $37^{\circ} \mathrm{C}$ with $5 \% \mathrm{CO}_{2}$. To remove non-adherent cells, the supernatants were replaced for the first time after 5 days of culture. The adherent cell clones that exhibited spindle-shaped growth were detached using cell scrapers and transferred to new 6-well plates. When the cells reached 70\%-80\% confluence, they were detached using $0.25 \%$ trypsin (Sigma) and cultivated in $25-\mathrm{cm}^{2}$ culture flasks (Corning Inc.-Life Science, Oneonta, NY, USA) and labeled as P1 (passage 1). We used P3 cells to conduct the experiments described next. To measure the expression of octamer-binding transcription factor 4 (Oct-4) mRNA, we used reverse-transcription polymerase chain reaction (RT-PCR). Rat lung fibroblasts (RFL-6; ATCC, Manassas, VA, USA) were used as the negative control.

\section{Flow cytometry analysis}

We used flow cytometry in order to detect the specific surface antigens of rAFMSCs (P3). Cells in suspension were incubated with fluorescein isothiocyanate (FITC)-conjugated antibodies against CD14, CD19, CD34, CD44, CD45, and CD90, and phycoerythrin (PE)-conjugated antibodies against CD29, CD73, CD105, and CD166 (BD Biosciences, San Diego, CA, USA) at $4^{\circ} \mathrm{C}$ for $1.5 \mathrm{~h}$. Thereafter, the cells were analyzed using a flow cytometer (Guava EasyCyte; Millipore, Billerica, MA, USA); the related isotype controls were used as the negative control.

\section{Differentiation potential of rAFMSCs}

To induce rAFMSCs to differentiate into adipogenic and osteogenic cell lineages, cells were cultured for 3 weeks in either an adipogenic medium $[\alpha$-modified minimum essential medium ( $\alpha$-MEM; Gibco) containing $10 \% \mathrm{FBS}$ and $1 \mu \mathrm{mol} / \mathrm{L}$ dexamethasone, $5 \mu \mathrm{g} / \mathrm{mL}$ insulin, $0.5 \mathrm{mmol} / \mathrm{L}$ isobutylmethylxanthine, and $60 \mu \mathrm{mol} / \mathrm{L}$ indomethacin (all 4 reagents from Sigma)], or an osteogenic medium ( $\alpha$-MEM containing 10\% FBS and $0.1 \mu \mathrm{mol} / \mathrm{L}$ dexamethasone, $10 \mathrm{mmol} / \mathrm{L} \beta$-glycerol phosphate, and $50 \mu \mathrm{mol} / \mathrm{L}$ ascorbate; Sigma). In the case of adipogenic differentiation, intracellular accumulation of lipid droplets was examined by means of Oil Red O staining, whereas in the case of osteogenic differentiation, alizarin red staining was used to observe calcium mineralization.

\section{Chromosomal analysis}

We prepared P3 and P15 rAFMSCs for the purpose of chromosomal analysis, as previously described [38]. The rAFMSCs were treated with $0.1 \mathrm{mg} / \mathrm{mL}$ colchicine (Sigma) at $37^{\circ} \mathrm{C}$ for $3 \mathrm{~h}$ and then incubated with $0.06 \mathrm{~mol} / \mathrm{L} \mathrm{KCl}$ at $37^{\circ} \mathrm{C}$ for $30 \mathrm{~min}$. Next, metaphase chromosomes were analyzed using $\mathrm{G}$ banding and Giemsa staining; we examined a minimum of 20 metaphases in each sample by using an 80i microscope (Nikon, Tokyo, Japan) and then analyzed them by using Genikon software (Nikon).

\section{Animal model and rAFMSC transplantation}

We maintained 60 female Sprague-Dawley rats at $21^{\circ} \mathrm{C}-25^{\circ} \mathrm{C}$ and $40 \%-60 \%$ relative humidity in a 12 -h light/dark cycle and provided them with water and food ad libitum. After 1 week of conditioning, the rats were randomly sorted into 4 groups (15 rats/group), control (group I), emphysema (group II), emphysema + rAFMSC transplantation for 20 days (group III), and emphysema + rAFMSC transplantation for 40 days (group IV).

A custom-designed cigarette-smoke chamber [39] and lipopolysaccharide (LPS; Sigma) stimuli were used for generating the rat model of emphysema [40]. In this study, we used commercially available cigarettes (XiongShi; China Tobacco Zhejiang Industrial. Co., LTD, China) that contained $0.7 \mathrm{mg}$ of nicotine and $8 \mathrm{mg}$ of tar per cigarette. We performed the cigarette-smoke exposure and intratracheal LPS instillation as follows, rats in groups II, III, and IV were placed in the cigarette-smoke chamber $(60 \mathrm{~cm} \times 50 \mathrm{~cm} \times 40 \mathrm{~cm})$, and after the rats had settled, the smoke of 5 cigarettes was successively delivered in $12 \mathrm{~min}$. After an interval of $10 \mathrm{~min}$, the smoke of 5 new cigarettes was delivered into the chamber. The rats were exposed to 20 cigarettes over $90 \mathrm{~min}$ once a day for each smoke exposure and for 7 days per week for 12 weeks. During the exposure, the concentration of carbon monoxide was maintained almost constant, after 30,60 , and $90 \mathrm{~min}$ exposures, the concentrations were $402 \pm 19$, $399 \pm 12$, and $408 \pm 14 \mathrm{ppm}$, respectively, as measured using a carbon monoxide detector (CTB-999; INDUSTRIAL SCIENTIFIC. Co., LTD, Shanghai, China). On the last day of the $4^{\text {th }}$ and $8^{\text {th }}$ weeks, each rat in groups II, III, and IV was temporarily anesthetized with $5.0 \%$ isoflurane, after which the rats were intratracheally instilled with $200 \mu \mathrm{L}$ of $1 \mu \mathrm{g} / \mu \mathrm{L}$ LPS in sterile phosphate-buffered solution (PBS). The rats in group I received clean air throughout the experimental period.

Y-chromosome-positive rAFMSCs were transplanted into the rats of the emphysema groups. Each rat in groups III and IV was intratracheally instilled with rAFMSCs $\left(4 \times 10^{6}\right.$ in $200 \mu \mathrm{L}$ of PBS), and after transplantation for 20 days and 40 days, the rats were sacrificed by intraperitoneal injection of $10.0 \%$ chloral hydrate. The left lungs were removed and fixed in $4 \%$ paraformaldehyde for use 
in histological examinations and immunohistochemical and immunofluorescence staining. The right lungs were stored at $-80^{\circ} \mathrm{C}$ for use in PCR and western blotting analyses.

\section{Histological examinations}

The left lungs were perfused intratracheally with $4 \%$ paraformaldehyde at a constant pressure of $25 \mathrm{~cm} \mathrm{H}_{2} \mathrm{O}$ for $1 \mathrm{~h}$, and then immersed in paraformaldehyde for $24 \mathrm{~h}$ to fix them completely. After fixation, the left-lung blocks were embedded in paraffin and cut into 4- $\mu$ m-thick sections. Three discontinuous paraffin-embedded sections of each lung-tissue sample were stained with hematoxylin and eosin (H\&E) in order to assess the morphological changes in the lungs. We examined 5 fields of view in each of the 3 sections from each lung sample by using a light microscope (Olympus, Tokyo, Japan), and we avoided selecting fields containing bronchi and large blood vessels. We obtained the mean linear intercept (MLI), which indicates the average distance between opposing walls of a single alveolus and is a measure of pulmonary airspace enlargement [41]. Moreover, we obtained the mean alveolar airspace (MAA), which is also a measure of pulmonary airspace enlargement [39].

\section{Quantitative real-time PCR}

Total RNA was extracted from each right-lung sample by using TRIzol reagent (Invitrogen, Carlsbad, CA, USA) according to the manufacturer's protocols. The final RNA purity and concentrations were determined using a spectrophotometer. Next, cDNA was synthesized from the total RNA by using the PrimeScript ${ }^{\mathrm{TM}} \mathrm{RT}$ reagent Kit with gDNA Eraser (TaKaRa, Otsu, Japan) according to the manufacturer's instructions. Quantitative real-time PCR analysis was performed using previously described parameters [35] and real-time PCR amplification equipment (MX3000P; Agilent Technologies, Inc., Santa Clara, CA, USA). The following primers were used (Invitrogen), SPA (GenBank, NM_001270647.1), 5'-TCGGTGTCCCAGGA TTTAG-3' (forward) and 5'-CAGGGTGGCTGCTGTT AGT-3' (reverse); SPC (GenBank, NM_017342.2), 5'CAGACACCATCGCTACCTT-3' (forward) and 5'-TAGC CAAAGCCTCAAGACT-3' (reverse); TTF1 (GenBank, XM_006233882.1), 5'-CATCAGATTCTGCAAACAATGG3' (forward) and 5'-AGGAGTCTGGCCTTCAATCA-3' (reverse); GAPDH (GenBank, NM_017008.4), 5'-GTTCA ACGGCACAGTCAAG-3' (forward) and 5'-GCCAGTAG ACTCCACGACAT-3' (reverse). All analyses were performed in triplicate. Glyceraldehyde-3-phosphate dehydrogenase $(G A P D H)$ was used as a reference gene. The relative expression of SPA, SPC, and TTF1 mRNAs was calculated using the $2^{-\Delta \Delta \mathrm{Ct}}$ method.

\section{Immunohistochemistry}

We performed immunohistochemical staining in order to examine the expression of SPA and SPC proteins in formalin-fixed, paraffin-embedded sections of each leftlung sample. Sections were deparaffinized and rehydrated using a graded series of ethanol, and this was followed by a high-pressure antigen-retrieval step. Endogenous peroxidase activity was blocked by incubating sections with $3 \%$ hydrogen peroxide for $15 \mathrm{~min}$. The sections were next blocked with $10 \%$ goat serum (ZSGB-BIO, Beijing, China) for $1 \mathrm{~h}$, incubated (overnight, $4^{\circ} \mathrm{C}$ ) with rabbit anti-rat SPA or SPC primary antibodies (1:500; Santa Cruz Biotechnology Inc., Santa Cruz, CA, USA), and then stained with an anti-rabbit IgG secondary antibody (SP-9000 kit; ZSGB-BIO) and 3,3'-diaminobenzidine (DAB; ZSGB-BIO). Hematoxylin was used for counterstaining. To calculate the percentages of SPA- and SPC-positive cells, we used a light microscope and counted the SPA- and SPC-positive cells present among a total of 400 cells in 10 different lung samples, and we used 10 randomly selected alveolus fields in the case of each lung sample.

\section{Western blotting}

Proteins were extracted from each right-lung sample by homogenizing the samples in ice-cold lysis buffer (50 mmol/L Tris, pH 7.4, $150 \mathrm{mmol} / \mathrm{L} \mathrm{NaCl}, 0.1 \%$ sodium dodecyl sulfate, $1 \mathrm{mmol} / \mathrm{L}$ EDTA, $1 \%$ sodium deoxycholate, and $1 \%$ Triton $\mathrm{X}-100$; Invitrogen) containing a proteaseinhibitor cocktail $(1 \mathrm{mmol} / \mathrm{L}$ phenylmethylsulfonyl fluoride, $1 \mathrm{mg} / \mathrm{L}$ leupeptin, and $1 \mathrm{mg} / \mathrm{L}$ aprotinin; Beyotime, Nantong, China). The homogenates were centrifuged for $15 \mathrm{~min}$ at $12,000 \mathrm{rpm}$ and the supernatants were collected. The protein concentration in samples was determined by using a micro BCA protein assay kit (Pierce, Rockford, IL, USA) according to the manufacturer's protocol. Next, equal amounts of protein $(20 \mu \mathrm{g})$ from each sample were heated at $100^{\circ} \mathrm{C}$ for $5 \mathrm{~min}$ and then separated by electrophoresing them on $8 \%$ sodium dodecyl sulfatepolyacrylamide gels. The separated proteins were electrotransferred to nitrocellulose membranes and blocked with Tris-buffered saline containing Tween-20 (TBS-T) and 5\% bovine serum albumin (BSA) for $2 \mathrm{~h}$ at room temperature. The membranes were then incubated with primary antibodies against SPA and SPC (1:200 in TBS-T; Santa Cruz) and $\beta$-actin (1:1000; Abcam, Cambridge, MA, USA) overnight at $4^{\circ} \mathrm{C}$ on an orbital shaker. After washing 3 times for 10 min each in TBS-T, the membranes were incubated with horseradish peroxidase-conjugated goat anti-rabbit $\operatorname{IgG}(\mathrm{H}+\mathrm{L})$ (Pierce) for $1 \mathrm{~h}$ at room temperature on an orbital shaker. After washing 5 times with TBS-T, immunoreactive bands on the membrane were detected using an enhanced chemiluminescence solution (Amersham Pharmacia Biotech, Buckinghamshire, UK), visualized by means of X-ray-film exposure, and analyzed using an UVP-GDS8000 gel-analysis system (Ultra-Violet Products Ltd., Cambridge, UK). Protein expression levels were analyzed by performing densitometry and the values 
were normalized relative to those measured for $\beta$-actin, which was used as the loading control.

\section{Reverse-transcription PCR}

Total RNA was extracted from each right-lung sample as described above and PCR was performed using previously described parameters [42] and PCR amplification equipment (MJ-PTC200; Bio-Rad, Hercules, CA, USA). The following primers were used, Oct-4 (GenBank, NM_001009178.2), 5'-GAAGGATGTGGTCCGAGTGT-3' (forward) and 5'-GTGAAGTGAGGGCTCCCATA-3' (reverse); Sex determining region Y (Sry) (GenBank, NM_012772.1), 5'-GCAATGGGACAACAACCTAC-3' (forward) and 5'-TGTTTCTGCTGTAGTGGGTATC-3' (reverse); GAPDH (GenBank, NM_017008.4), 5'-GTTCA ACGGCACAGTCAAG-3' (forward) and 5'-GCCAGTAG ACTCCACGACAT-3' (reverse). GAPDH was amplified for the purpose of normalizing the target genes in each group. The Oct-4, Sry, and GAPDH PCR products were 183, 138, and 136 bp long, respectively. The amplified PCR products were electrophoretically separated on $1.5 \%$ agarose gels, and the band densities were determined using the UVP-GDS8000 gel-analysis system.

\section{TUNEL/SPC immunofluorescence staining}

AECII apoptosis in each group was detected using terminal deoxynucleotidyl transferase dUTP-mediated nick-end labeling (TUNEL; Beyotime)/SPC doublestaining as described [43]. Paraffin-embedded left-lung sections were deparaffinized and rehydrated and then subjected to the high-pressure antigen-retrieval step and proteinase $\mathrm{K}(20 \mu \mathrm{g} / \mathrm{mL})$ treatment for $20 \mathrm{~min}$. The sections were next incubated with the rabbit anti-rat SPC primary antibody (1:300; Santa Cruz) overnight at $4^{\circ} \mathrm{C}$ and then with the FITC-conjugated anti-rabbit IgG secondary antibody (1:500; Santa Cruz) for $1 \mathrm{~h}$ at $37^{\circ} \mathrm{C}$, and this was followed by incubation with $50 \mu \mathrm{L}$ of the TUNEL reaction mixture at $37^{\circ} \mathrm{C}$ for $1 \mathrm{~h}$ in a humidified chamber. Lastly, the sections were counterstained with 4',6-diamino2-phenylindole (DAPI; Sigma) and examined using a fluorescence microscope (Axio vert; Carl Zeiss, Jena, Germany). We randomly selected 100 images from 10 different lung samples, and then chose 10 discontinuous areas of each lung sample for the analysis. The percentage of AECII apoptosis was determined by dividing the number of apoptotic AECII, which were positive for both TUNEL and SPC, by the total number of DAPI-positive cells.

\section{In situ hybridization and immunofluorescence}

Fluorescence in situ hybridization (FISH) for Y chromosome (Y-FISH) was performed as described [33] by using the Sry mRNA in situ hybridization detection kit (BOSTER, Wuhan, China) according to the manufacturer's protocols. Paraffin-embedded left-lung sections were deparaffinized and rehydrated, blocked with $3 \%$ hydrogen peroxide for $10 \mathrm{~min}$, and digested with proteases (diluted using $3 \%$ citric acid) for $15 \mathrm{~min}$ at room temperature. The sections were rinsed 3 times in PBS, and then $20 \mu \mathrm{L}$ of the prehybridization solution was incubated with each section for $4 \mathrm{~h}$ at $42^{\circ} \mathrm{C}$ in a humidified chamber; to perform hybridization, we incubated $20 \mu \mathrm{L}$ of Sry oligonucleotide probes with the sections overnight at $42^{\circ} \mathrm{C}$, with the samples being sealed with coverslips (BOSTER). After removing the coverslips, the sections were immersed sequentially in $2 \times$ standard saline citrate (SSC; BOSTER) for $10 \mathrm{~min}, 0.5 \times$ SSC for $15 \mathrm{~min}, 0.2 \times$ SSC for $30 \mathrm{~min}$ (all at $37^{\circ} \mathrm{C}$ ), and then incubated with cy3-conjugated rat IgG streptavidin-biotin complex (SABC-cy3; Eton Bioscience Inc., San Diego, CA, USA) for $45 \mathrm{~min}$ at $37^{\circ} \mathrm{C}$. Lastly, the sections were counterstained with DAPI and examined using an IX71 fluorescence microscope (Olympus). To combine this hybridization with immunostaining for SPC, sections were incubated with the anti-rat SPC primary antibody (1:500; Santa Cruz) overnight at $4^{\circ} \mathrm{C}$ and then with the FITC-conjugated anti-rabbit IgG secondary antibody (1:500; Santa Cruz) for $1 \mathrm{~h}$ at room temperature. We randomly selected 100 images from 10 different lung samples and analyzed 10 discontinuous areas in each lung sample. The percentage of differentiation was determined by counting the cells that were positive for both Y-FISH and SPC and dividing this number by the total number of DAPI-positive cells.

\section{Statistical analysis}

Data are expressed as means \pm SEM and were analyzed for statistical significance by means of one-way analysis of variance (ANOVA) and independent-sample $t$-tests. Multiple comparisons in ANOVA were performed using the Student-Newman-Keuls test. $P<0.05$ was considered statistically significant.

\section{Results \\ Culturing rAFMSCs}

Colonies of rAFMSCs began to appear after the cells had been cultured for 5 days in DMEM medium containing $20 \% \mathrm{FBS}$ and $4 \mathrm{ng} / \mathrm{mL}$ bFGF (Figure 1A). When the cells reached $80 \%-90 \%$ confluence, spindle-shaped cells (P3) became dominant and they grew spirally after 2 weeks of culture (Figure 1B).

\section{Phenotypic characterization of rAFMSCs}

The surface antigenic characteristics of rAFMSCs at P3 were analyzed using flow cytometry. The results revealed that the cells were positive for these surface antigens, CD29 (99.4\% $\pm 0.4 \%)$, CD 44 (99.3\% $\pm 0.4 \%)$, CD73 (76.7\% $\pm 4.5 \%)$, CD90 (97.5\% $\pm 1.6 \%), C D 105(74.5 \% \pm 4.7 \%)$, and CD166 $(89.3 \% \pm 3.1 \%)$; by contrast, they were negative $(0 \%)$ for CD14, CD19, CD34, and CD45 (Figure 2A). Moreover, 


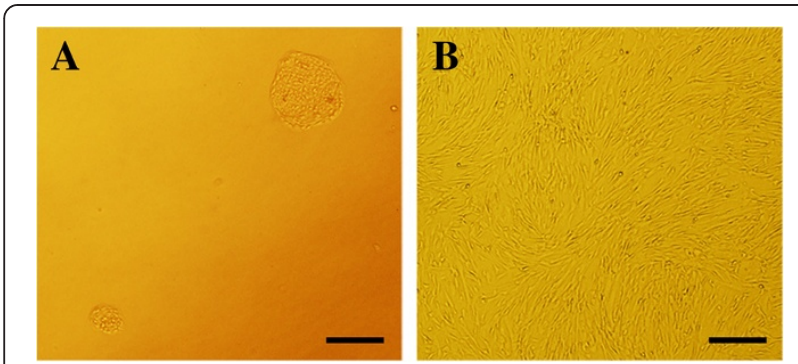

Figure 1 Culture of rAFMSCs. (A) Morphological characterization of rAFMSCs. After rAFMSCs were cultured 5 days, colonies began to appear. (B) Morphology of rAFMSCs. After 2 weeks of culture, the cells (P3) were spindle shaped and exhibited spiral growth. Scale bars, $200 \mu \mathrm{m}$.

RT-PCR results showed that the Oct-4 mRNA was strongly expressed by the rAFMSCs (Figure 2B).

\section{Differentiation potential of rAFMSCs}

To evaluate the differentiation potential of rAFMSCs, cells at P3 were induced to differentiate into adipocytes and osteocytes. After rAFMSCs were cultured in an adipogenic medium for 3 weeks, Oil Red O-positive intracellular lipid droplets were observed (Figure 3A). Similarly, after rAFMSCs were cultured in an osteogenic medium for 3 weeks, most of the differentiated cells appeared cubical and exhibited a dull-red alizarin-red staining that indicated calcium mineralization (Figure 3B).

\section{Chromosomal analysis}

To identify the karyotype and to confirm chromosomal stability, we performed karyotype analysis on P3 and P15 rAFMSCs. The results revealed that rAFMSCs contained a normal diploid number of chromosomes $(2 n=42)$ and

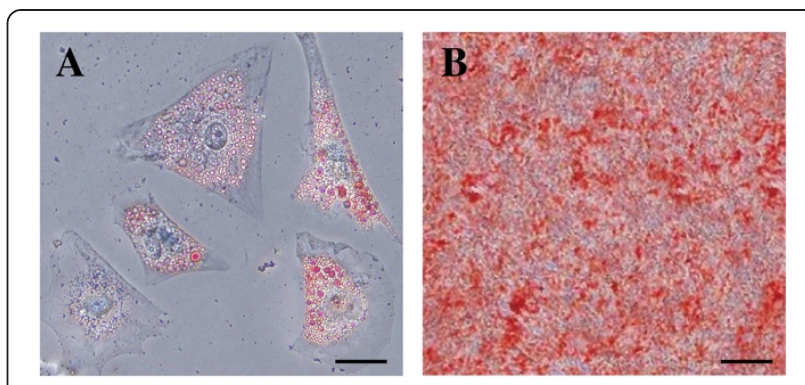

Figure 3 Differentiation potential of rAFMSCs. (A) Adipogenic differentiation, cells positive for Oil Red O staining. (B) Osteogenic differentiation, cells positive for alizarin red staining. Scale bars, $50 \mu \mathrm{m}$ (A) and $200 \mu \mathrm{m}$ (B).

maintained a normal karyotype (Y-chromosome-positive) at these distinct passages (data not shown).

\section{Histopathological changes}

After 12 weeks of cigarette-smoke exposure and 2 intratracheal LPS instillations, the airspace was enlarged markedly and the number of alveoli was decreased in the lung samples of the rats of the emphysema group (group II) (Figure 4B). When compared with the samples from group I (Figure 4A), the samples from group II exhibited numerous merged alveoli and the formation of a few bullae, which was consistent with the pathological characteristics of emphysema. However, both of the emphysema characteristics were partly alleviated after rAFMSC transplantation, as shown in Figure 4C and especially in Figure 4D. Quantitative analyses of lung histomorphology revealed that the MLI and MAA of group II were significantly higher than those of the control group (95\% confidence intervals, MLI, $51.42 \sim 64.82$; MAA, $8219.06 \sim 9136.90 ; P<0.01)$. However, the MLI and MAA of groups III and IV were significantly

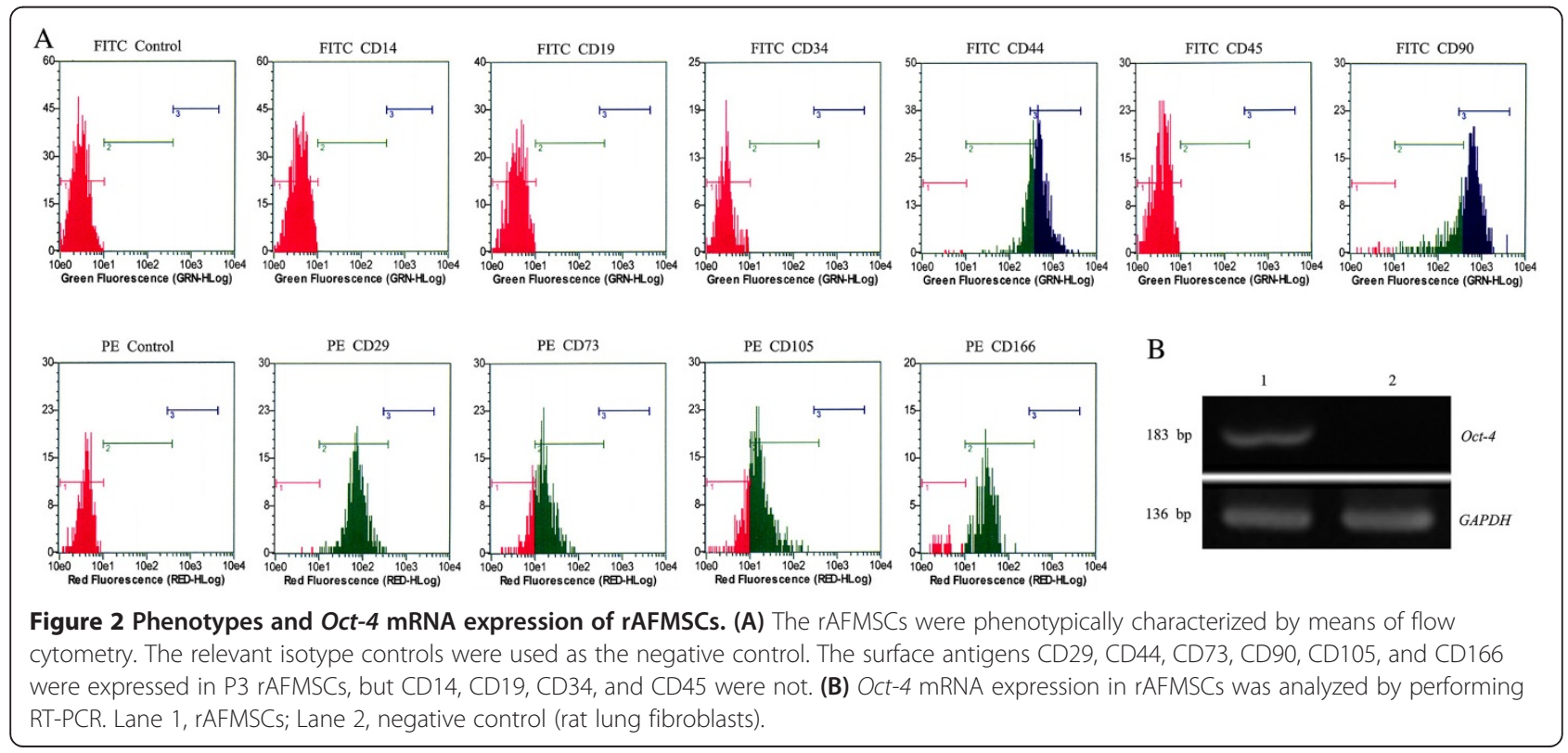



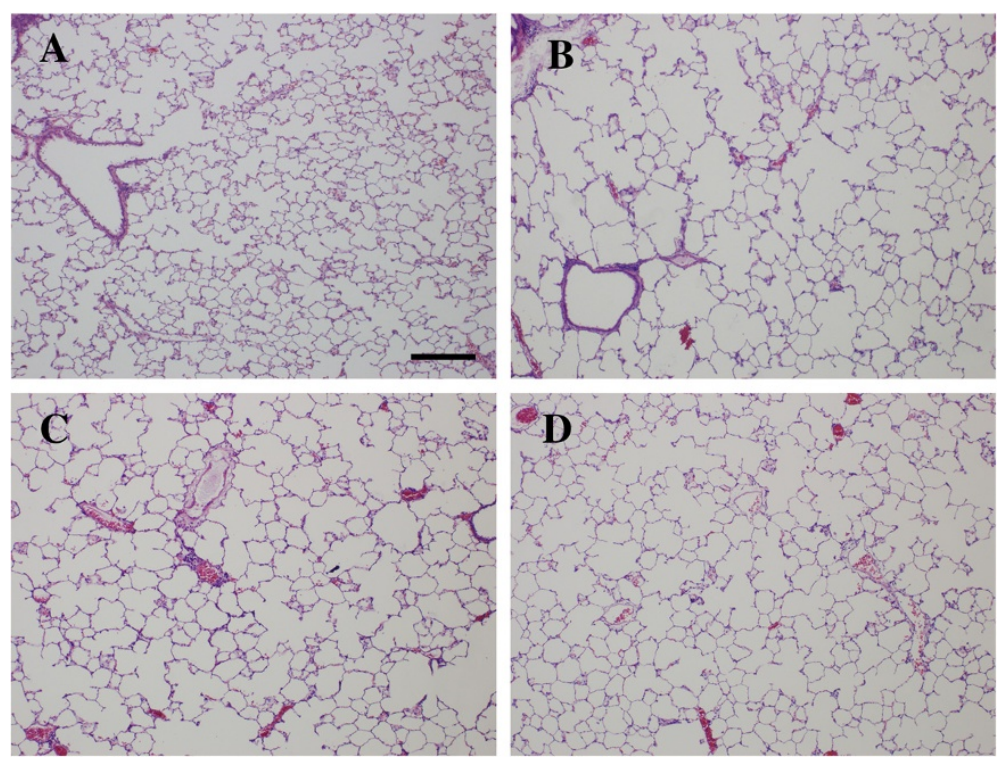

Figure 4 Histopathologic changes of lung tissues in rats of various groups. (A) Control group (group I). (B) Emphysema group (group II). Airspace was markedly enlarged and the amount of alveoli was decreased after cigarette-smoke exposure and intratracheal LPS instillation. (C) Emphysema + rAFMSC transplantation for 20 days (group III). The features of emphysema were partly diminished after rAFMSC transplantation for 20 days. (D) Emphysema + rAFMSC transplantation for 40 days (group IV). The features of emphysema were decreased substantially after rAFMSC transplantation for 40 days. Scale bars, $200 \mu \mathrm{m}$.

lower than those of group II (95\% confidence intervals, group III, MLI, $-35.47 \sim-22.07$; MAA, $-3900.76 \sim-2982.92$; group IV, MLI, $-48.42 \sim-35.02$; MAA, $-5648.48 \sim-4730.65$; $P<0.01)$, especially in group IV $(95 \%$ confidence intervals, MLI, $-19.93 \sim-5.94$; MAA, $-2227.04 \sim-1268.39$; $P<0.01$; Table 1).

\section{Expression of SPA, SPC, and TTF1 mRNAs}

High levels of $S P A, S P C$, and TTF1 mRNAs were expressed in samples from group I (control group), but these levels were markedly lower by comparison in the emphysema group (group II) (95\% confidence intervals, SPA, $-0.23 \sim-0.17 ; \quad \mathrm{SPC}, \quad-0.30 \sim-0.28$; TTF1, $-0.32 \sim-0.28 ; P<0.05)$. After rAFMSC transplantation (groups III and IV), the expression levels of

Table 1 Quantitative analyses of lung histomorphology

\begin{tabular}{lll}
\hline Group & MLI $(\boldsymbol{\mu m})$ & MAA $\left(\mu \mathbf{m}^{2}\right)$ \\
\hline I & $56.53 \pm 3.35$ & $4872.28 \pm 194.47$ \\
II & $114.66 \pm 12.22^{*}$ & $13550.27 \pm 619.55^{*}$ \\
III & $85.88 \pm 6.07^{* *}$ & $10108.42 \pm 691.21^{* *}$ \\
IV & $72.94 \pm 4.60^{* * \#}$ & $8360.70 \pm 445.85^{* * *}$ \\
\hline
\end{tabular}

Measurement of the parameters MLI and MAA revealed that rAFMSCs could alleviate lung injury in rats with emphysema after being transplanted for 20 and 40 days. Group I, control. Group II, emphysema. Group III, emphysema + rAFMSC transplantation for 20 days. Group IV, emphysema + rAFMSC transplantation for 40 days. Values are presented as means $\pm \operatorname{SEM}(n=10)$. ${ }^{P} P<0.01$ versus group I, ${ }^{*} P<0.01$ versus group II, ${ }^{\#} P<0.01$ versus group III. MLI = Mean linear intercept; $M A A=$ mean alveolar airspace.
$S P A, S P C$, and TTF1 mRNAs were significantly higher than those measured in the case of group II ( $95 \%$ confidence intervals, group III, SPA, $0.03 \sim 0.09$; SPC, $0.02 \sim 0.07$; TTF1, $0.06 \sim 0.12$; group IV, SPA, $0.06 \sim 0.12$; SPC, $0.11 \sim 0.15$; TTF1, $0.12 \sim 0.17 ; P<0.05)$. Compared with rAFMSC transplantation for 20 days (group III), the transplantation for 40 days (group IV) significantly increased the expression of SPA, SPC, and TTF1 mRNAs (95\% confidence intervals, SPA, $0.01 \sim 0.07$; SPC, $0.07 \sim 0.14$; TTF1, $0.01 \sim 0.06 ; P<0.05$ ) (Figure 5).

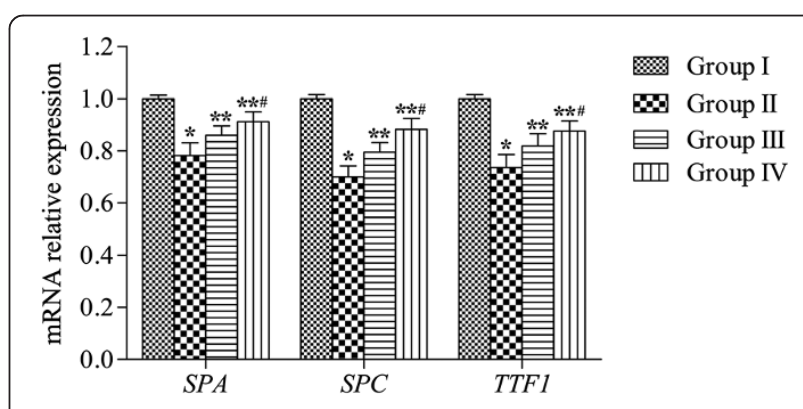

Figure 5 SPA, SPC, and TTF1 mRNA expression in lung tissues.

SPA, SPC, and TTF1 mRNA expression levels in lung tissues were determined using quantitative real-time PCR. The relative expression of SPA, SPC, and TTF1 mRNAs was calculated using the $2^{-\Delta \Delta C \mathrm{t}}$ method. Values are presented as average expression levels of the mRNAs (means \pm SEM, $\mathrm{n}=12$ ); ${ }^{*} P<0.05$ versus group $\mathrm{I},{ }^{* *} P<0.05$ versus group II, ${ }^{P} P<0.05$ versus group III. 
Immunohistochemical analysis of SPA and SPC expression After immunohistochemical staining, SPA- and SPCpositive cells exhibited a yellowish-brown color in the cytoplasm, and these cells were mainly located in the alveolar corner of AECII (Figure 6A-D). The expression of SPA and SPC was weaker in group II (Figure 6B) than in group I (Figure 6A). However, after rAFMSC transplantation (groups III and IV), the expression of SPA and SPC increased significantly compared with that in the emphysema group (group II), especially in the case of group IV. Similarly, the percentages of SPA- and SPC-positive cells were markedly lower in group II $(7.0 \% \pm 0.8 \%$ and $4.4 \% \pm 1.1 \%)$ than in group I $(12.2 \% \pm 1.2 \%$ and $8.5 \% \pm 1.4 \%)$ (95\% confidence intervals, SPA, $-6.11 \% \sim-4.28 \%$; SPC, $-5.17 \% \sim-3.07 \%$; $P<0.05$; Figure $6 \mathrm{E}, \mathrm{F})$. However, the percentages of SPA- and SPC-positive cells were significantly higher in group III $(8.1 \% \pm 1.0 \%$ and $5.8 \% \pm 0.9 \%)$ and group IV $(9.2 \% \pm 0.8 \%$ and $7.1 \% \pm 1.0 \%)$ than in group II (95\% confidence intervals, group III, SPA, 0.18\% 2.01\%; SPC, 0.35\% 2.44\%; group IV, SPA, $1.33 \% \sim 3.16 \%$; SPC, $1.62 \% \sim 3.72 \%$; $P<0.05$ ), especially in group IV (95\% confidence intervals, SPA, $0.23 \% \sim 2.06 \%$; SPC, $0.22 \% \sim 2.32 \%$; $P<0.05)$. These results indicate that after transplantation, rAFMSCs might have differentiated into AECII-like cells in the lung tissues of rats of groups III and IV, and expressed SPA and SPC.

\section{Quantification of SPA and SPC expression}

SPA and SPC expression was quantified by performing western blotting analysis. The results in Figure 7 show that the expression of SPA and SPC was lower in the emphysema group $(66.96 \% \pm 3.54 \%$ and $60.58 \% \pm 3.96 \%)$ than in the control group (95\% confidence intervals, SPA, $-36.98 \% \sim-29.10 \%$; SPC, $-46.84 \% \sim-32.00 \%$; $P<0.05$ ). Conversely, rAFMSC treatment increased the expression levels of SPA and SPC (group III, 77.16\% $\pm 3.59 \%$ and $76.03 \% \pm 4.86 \%$; group IV, $88.15 \% \pm 3.00 \%$ and $87.90 \% \pm 4.74 \%)$ as compared with the expression in group II (95\% confidence intervals, group III, SPA, 6.26\% 14.14\%; SPC, 9.03\% 23.87\%; group IV, SPA, $17.25 \% \sim 25.13 \%$; SPC, $20.89 \% \sim 35.74 \% ; P<0.05)$, especially in group IV (95\% confidence intervals, SPA, 7.05\% 14.93\%; SPC, 4.44\% 19.29\%; $P<0.05)$.

\section{Sry mRNA expression}

To determine whether rAFMSCs integrated into lung tissues after transplantation, we used RT-PCR to analyze the expression of Sry mRNA (Figure 8). When rAFMSCs were transplanted for 20 days (group III), the expression of Sry mRNA could be detected, and the expression level was increased significantly in group IV $(t=-5.768 ; P<0.01)$. However, Sry mRNA was not expressed in groups I and II, but it was strongly expressed in a positive-control group (male rats).

\section{Apoptosis of type II alveolar epithelial cells}

AECII apoptosis was measured using TUNEL and SPC double-immunofluorescence staining. Apoptotic AECII exhibited red fluorescence in the cell nuclei (TUNEL-positive) and green fluorescence in the cytoplasm (SPC-positive) (Figure 9A-D). The percentage of AECII apoptosis in group II was significantly higher than that in group I (95\% confidence intervals, 12.96\% 16.44\%; $P<0.01$; Figure 9E). After rAFMSC transplantation (groups III and IV), the apoptosis percentages were markedly lower than that in group II (95\% confidence intervals, group III, $-9.94 \% \sim-6.46 \%$; group IV, $-13.74 \% \sim-10.26 ; P<0.01$ ), especially in group IV (95\% confidence intervals, $-5.54 \% \sim-2.06 \% ; P<0.01$ ). These results indicated that AECII apoptosis decreased in rats after rAFMSC transplantation.

\section{Differentiation of rAFMSCs in lung tissues}

To further determine how the lung injury caused by emphysema can be repaired by transplanted rAFMSCs after integration, we analyzed Y-FISH and SPC doubleimmunofluorescence staining in lung sections. The integration of rAFMSCs (Y-chromosome-positive cells) into lung tissues of rats was detected by means of Y-FISH analysis (Figure 10). The results revealed that Y-FISHpositive cells were abundant in the lung sections of male rats (positive-control group; Figure 10E), but the cells were not detected in the sections from the rats of groups I and II (Figure 10A,B). After rAFMSCs were transplanted for 20 days (group III) or 40 days (group IV), the expression of Y-FISH-positive cells was significantly higher than that observed in groups I and II (group III, $t=-8.327$; group IV, $t=-8.209 ; P<0.01$; Figure 10C,D). Furthermore, the percentage of Y-FISH-positive cells in group IV was significantly higher than that in group III $(t=-2.675 ; P<0.05$; Figure 10F), which agrees with the Sry mRNA-expression results. These results revealed that the rAFMSCs had integrated into the lung tissues of the female rats in groups III and IV after being transplanted for 20 and 40 days, respectively.

To determine whether the rAFMSCs differentiated into AECII-like cells after transplantation, we examined the expression of SPC in Y-FISH-positive cells by performing double-immunofluorescence staining (Figure 10). After rAFMSCs were transplanted into lung tissues for 20 days (group III), Y-FISH and SPC double-positive cells were detected under the fluorescence microscope, and the percentage of these double-positive cells in the sections of the rats of group IV was higher than that measured in the case of group III $(t=-3.266 ; P<0.05$; Figure 10G).

\section{Discussion}

No drugs are currently available for reversing the progression of COPD and the chronic airflow limitation and emphysema associated with it. Therefore, novel techniques 

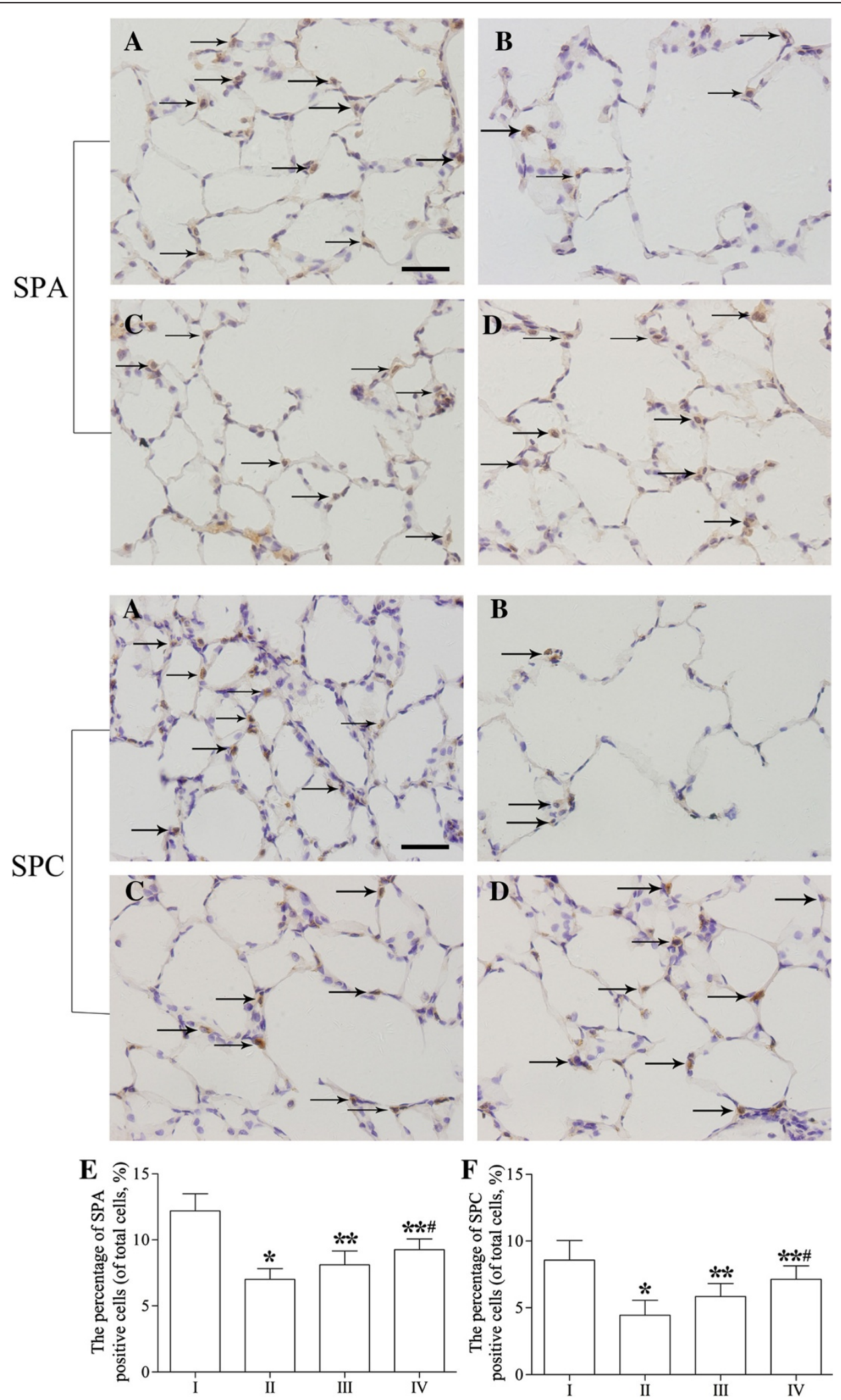

Figure 6 (See legend on next page.) 
(See figure on previous page.)

Figure 6 Expression of SPA and SPC proteins examined by means of immunohistochemical staining. (A) Control group (group I). SPA and SPC staining was strongly positive. (B) Emphysema group (group II). SPA and SPC were expressed at lower levels than in group I. (C) Emphysema + rAFMSC transplantation for 20 days (group III). SPA and SPC expression was increased after rAFMSC transplantation for 20 days. (D) Emphysema + rAFMSC transplantation for 40 days (group IV). SPA and SPC expression was increased substantially after rAFMSC transplantation for 40 days. (E) Percentages of SPA-positive cells in the 4 groups. The percentage of SPA-positive cells was significantly lower in group II than in group I $(P<0.05)$, but the percentage was markedly increased after rAFMSC transplantation for 20 and 40 days $(P<0.05)$. (F) Percentages of SPC-positive cells in the 4 groups. The percentage of SPC-positive cells was significantly lower in group II than in group I $(P<0.05)$, but the percentage was markedly increased after rAFMSC transplantation for 20 and 40 days $(P<0.05)$. Values are presented as average percentages of SPA- and SPC-positive cells (means \pm SEM, $n=10$ ); ${ }^{*} P<0.05$ versus group I, ${ }^{*} P<0.05$ versus group II, ${ }^{*} P<0.05$ versus group III. Scale bars, $50 \mu \mathrm{m}$.

that can be used for effectively treating COPD must be explored. Cigarette smoking is the primary risk factor for COPD, which is related to the inflammatory reactions of lung tissues [44]. LPS, which is a structural component of the outer membrane of gram-negative bacteria, plays key roles in injuring the epithelium and activating inflammatory cells to secrete inflammatory factors and proteases, which contribute to the pathogenesis of chronic bronchitis and emphysema [45]. In this study, emphysema was induced in rats by exposure to cigarette smoke and LPS.

Over the past few decades, stem cells have been used in regenerative medicine $[27,33,36,46]$. Previously, AFSCs were shown to differentiate into lung epithelial cells after implantation into lung tissue in vivo [33]. AFMSCs, which can be readily isolated from amniotic fluid, are multipotent stem cells that exhibit the characteristics of MSCs $[35,36]$. In this study, we isolated and identified rAFMSCs, which were derived from fetal male rats, and we showed that after transplantation, rAFMSCs could alleviate the lung injury caused by emphysema.

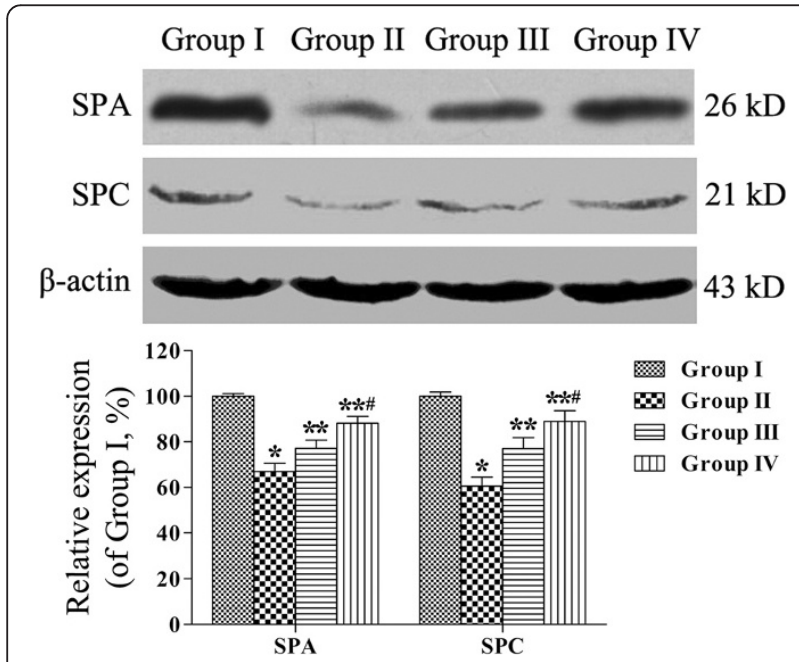

Figure 7 Quantification of SPA and SPC protein expression by means of western blotting analysis. The loading control used was $\beta$-actin. The expression of SPA and SPC proteins was analyzed by performing densitometry and normalizing the values relative to that of $\beta$-actin. All analyses were performed in triplicate. Values are presented as means \pm SEM $(n=10) .{ }^{*} P<0.05$ versus group I, ${ }^{* *} P<0.05$ versus group II, ${ }^{\#} P<0.05$ versus group III.
We isolated and purified rAFMSCs and analyzed their phenotypic characteristics, and the results revealed that the rAFMSCs did not express the surface antigens CD14, CD19, CD34, and CD45, but strongly expressed CD29, CD44, CD73, CD90, CD105, and CD166; this agrees with the results of Pan et al. [36]. Oct-4, a POU transcription factor, is a marker of pluripotent stem cells [47] that disappears quickly after cells differentiate [48]. Oct-4 has been reported to be expressed in embryonal carcinoma cells, ESCs, embryonic germ cells, and amniotic fluid stem cells, and to play a vital role in determining the fate of stem cells [49-51]. Here, Oct-4 mRNA was expressed in rAFMSCs at considerably higher levels than in rat lung fibroblasts, which revealed that rAFMSCs exhibit the stem cells' characteristics for differentiation. The isolated rAFMSCs could be induced to differentiate into adipocytes and osteocytes, which demonstrated that the differentiation potential of rAFMSCs was similar to that of AFSCs $[28,29]$.

We transplanted rAFMSCs into rats for 20 and 40 days by means of intratracheal instillation and then examined the morphological changes in lung tissue. The results revealed that the MLI and MAA measured in lung tissues were markedly improved in groups III and IV when compared with group II (emphysema group). Thus, we hypothesize that rAFMSC transplantation can be used for repairing the lung injury caused by emphysema, and that this transplantation stimulates the expression of pulmonary SPs in rats with emphysema.

SPs include SPA, SPB, SPC, and SPD and are synthesized and secreted by AECII in lung tissue. SPA and SPC, which are secreted specifically by AECII $[52,53]$, play critical roles in reducing the surface tension of alveoli. In this study, lung tissues expressed both SPA and SPC mRNAs and proteins after rAFMSC transplantation (groups III and IV) at levels markedly higher than those in the emphysema group (group II), which agreed with the morphological changes observed. TTF1 is vital for the induction of respiratory cells, including AECII, and it is expressed in lung tissues after AFSC transplantation [33,54]. Here, the TTF1 mRNA level in groups III and IV was considerably higher than that in group II.

Sry is the Y-chromosome-specific gene that determines the sex of animals [33]. Our results showed that Sry 


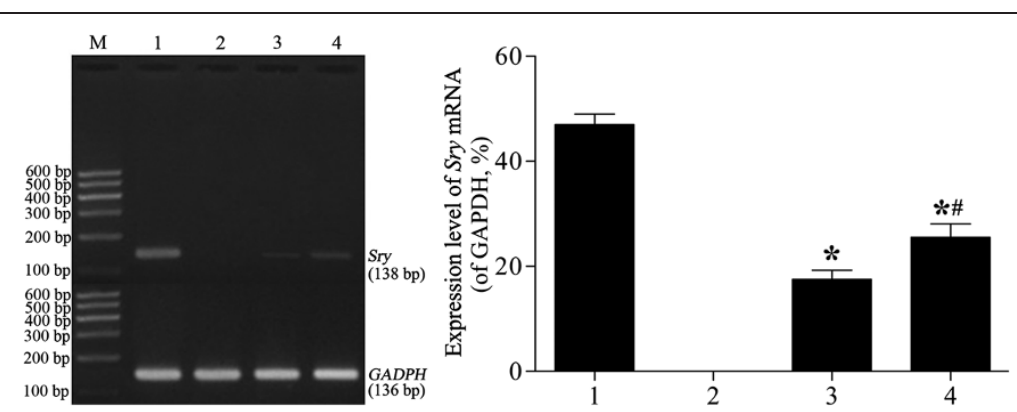

Figure 8 Sry mRNA expression. M, DNA ladder marker; Lane 1, positive-control group (male rats); Lane 2, control group (female rats); Lane 3, emphysema + rAFMSC transplantation for 20 days (group III); Lane 4, emphysema + rAFMSC transplantation for 40 days (group IV). The expression of Sry mRNA was analyzed by normalizing the values relative to that of GAPDH. Values are presented as average expression levels of Sry mRNA (means $\pm \mathrm{SEM}, \mathrm{n}=10) ;{ }^{*} P<0.01$ versus positive-control group, ${ }^{\#} P<0.01$ versus group III.

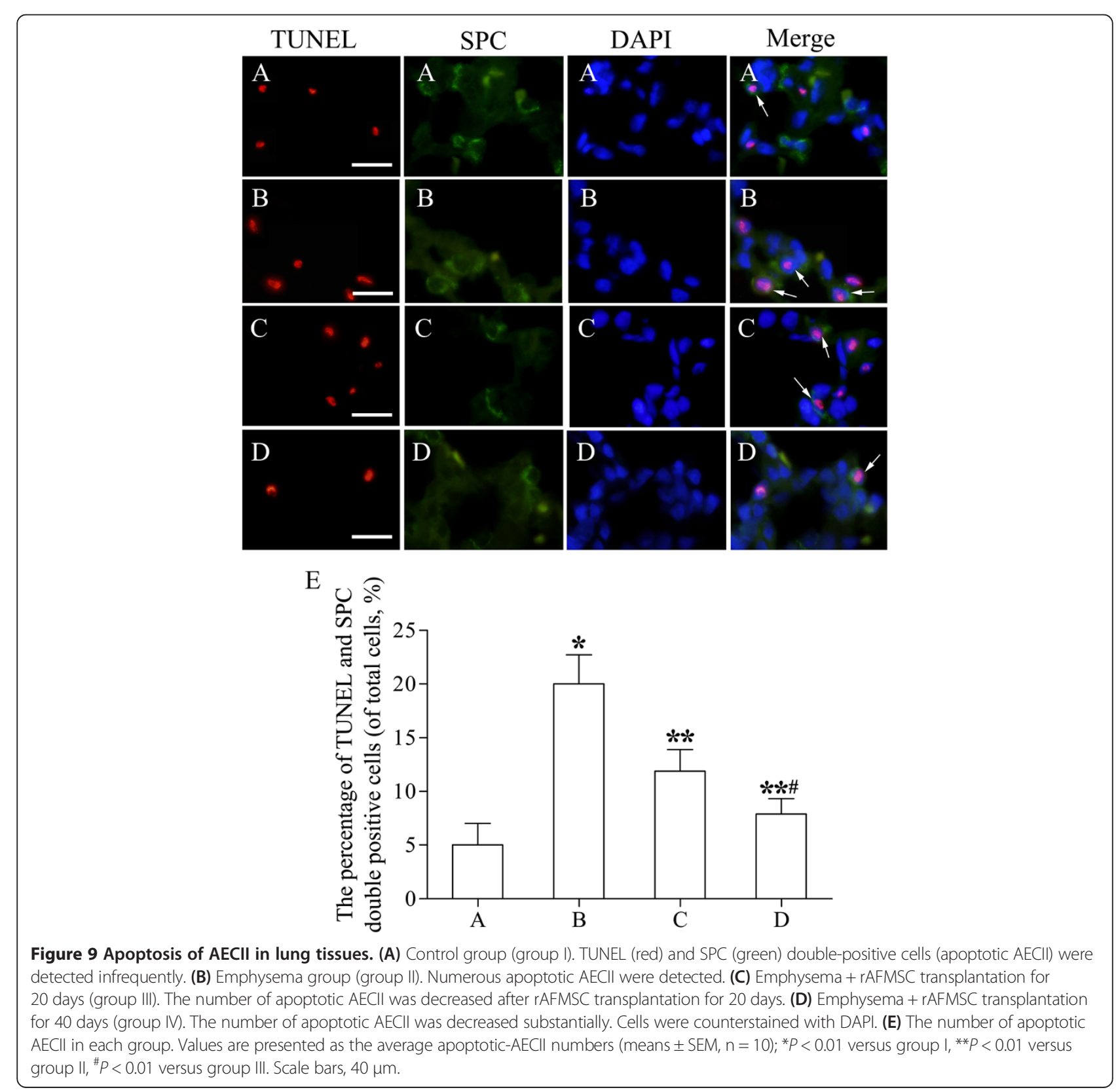



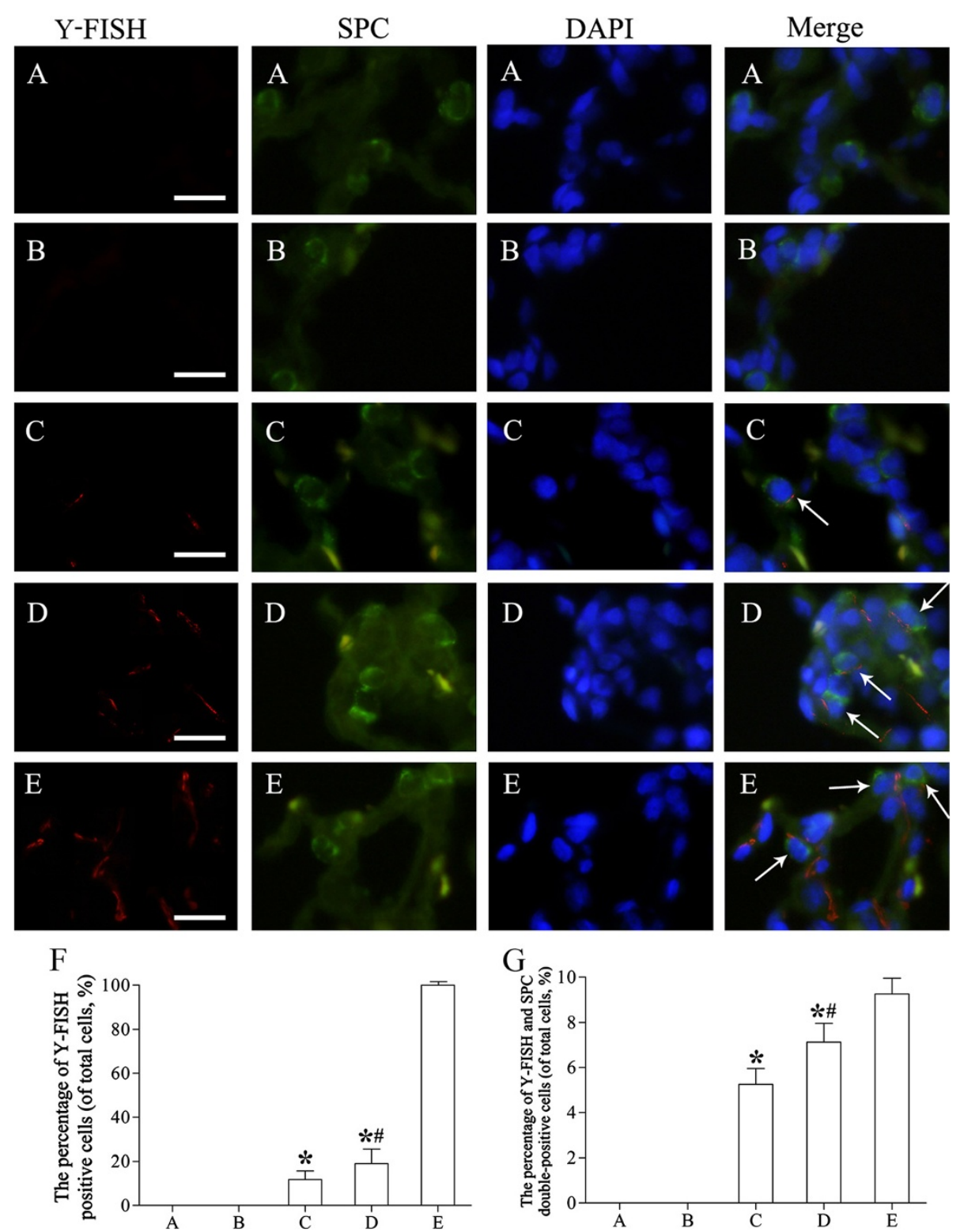

Figure 10 Y-FISH and SPC double-immunofluorescence staining in lung tissues. (A) Control group (group I). Y-FISH staining (red) was negative. Nuclei were counterstained with DAPI (blue). (B) Emphysema group (group II). Y-FISH staining was again negative. (C) Emphysema + rAFMSC transplantation for 20 days (group III). Y-FISH staining was weakly positive and a few Y-FISH-positive cells were also positive for SPC staining (green). (D) Emphysema + rAFMSC transplantation for 40 days (group IV). The number of Y-FISH-positive cells was increased substantially, and the number of Y-FISH and SPC double-positive cells was markedly higher than that in group III. (E) Positive-control group (male rats). Y-FISH staining was strongly positive. Cells were counterstained with DAPI. (F) The percentage of Y-FISH-positive cells in each group. (G) The percentage of Y-FISH and SPC double-positive cells in each group. Values are presented as average percentages of positive cells (means \pm SEM, $\mathrm{n}=10$ ); ${ }^{*} P<0.01$ versus group I, ${ }^{\#} P<0.05$ versus group III. Scale bars, $40 \mu \mathrm{m}$.

mRNA was strongly expressed after rAFMSC transplantation (groups III and IV), but it was not expressed in the absence of transplantation (groups I and II), which indicated that the transplanted rAFMSCs had integrated into lung tissues. Moreover, when we examined AECII apoptosis, the results showed that the percentage of TUNEL and SPC double-positive cells (apoptotic AECII) after rAFMSC integration was substantially lower than the percentage in the emphysema group.

To locate and count the AECII-like cells that were differentiated from the rAFMSCs in lung tissues, we performed immunostaining and observed SPC expression by rAFMSCs, and the identity of these cells was confirmed by means of Y-FISH in the lung tissues. The 
results indicated that rAFMSCs in the lung tissues might be able to differentiate into AECII-like cells or induce local regeneration of the lung alveolar epithelium after transplantation.

\section{Conclusions}

The results of this study suggest that transplanted rAFMSCs can alleviate the lung injury caused by emphysema; they do so by integrating into lung tissues, potentially differentiating into AECII-like cells or inducing local regeneration of the lung alveolar epithelium, inhibiting AECII apoptosis, and elevating the levels of SPA, SPC, and TTF1 mRNAs and SPA and SPC proteins. Thus, rAFMSC transplantation can potentially be used as a method for the treatment of COPD and in lung regenerative therapy.

\begin{abstract}
Abbreviations
COPD: Chronic obstructive pulmonary disease; AECI: Type I alveolar epithelial cells; AECII: Type II alveolar epithelial cells; AFMSCs: Amniotic fluid-derived mesenchymal stromal cells; ESCs: Embryonic stem cells; rAFMSCs: Rat amniotic fluid-derived mesenchymal stromal cells; Oct-4: Octamer-binding transcription factor 4; SPs: Surfactant proteins; SPA: Surfactant protein A; SPB: Surfactant protein B; SPC: Surfactant protein C; SPD: Surfactant protein D; TTF1: Thyroid transcription factor 1; BMMSCs: Bone marrow-derived mesenchymal stromal cells; AFSCs: Amniotic fluid-derived stromal cells; MSCs: Mesenchymal stromal cells; DMEM: Dulbecco's modified Eagle's medium; bFGF: Basic fibroblast growth factor; FITC: Fluorescein isothiocyanate; PE: Phycoerythrin; MLI: Mean linear intercept; MAA: Mean alveolar airspace; GAPDH: Glyceraldehyde-3-phosphate dehydrogenase; RT-PCR: Reverse transcription PCR; TUNEL: Terminal deoxynucleotidyl transferase dUTP-mediated nick end labeling; FISH: Fluorescence in situ hybridization; Y-FISH: Fluorescence in situ hybridization for Y chromosome.
\end{abstract}

\section{Competing interests}

The authors declare that they have no competing interests.

\section{Authors' contributions}

Conceived and designed the experiments, YQL, CG, WLX, JPY. Performed the experiments, YQL, CG, WLX, JPY, YJX, XJH, HQT. Analyzed the data, JPY, CC, YYM, YJX. Wrote the paper, YQL, CG. All authors read and approved the final manuscript.

\section{Acknowledgments}

This work was supported by grants from the National Natural Science Foundation of China (No. 81000016 and 81470241).

\section{Author details}

'Department of Respiratory Medicine, Zhejiang Provincial People's Hospital, No. 158, Shangtang Road, Hangzhou, Zhejiang 310014, P.R. China. ${ }^{2}$ The Second Clinical Medical College, Zhejiang Chinese Medical University, Hangzhou, Zhejiang 310053, P.R. China. ${ }^{3}$ Key Laboratory of Gastroenterology of Zhejiang Province, Zhejiang Provincial People's Hospital, Hangzhou, Zhejiang 310014, P.R. China.

Received: 28 June 2014 Accepted: 30 September 2014

Published online: 16 October 2014

\section{References}

1. Burgel PR: Pathogenesis of chronic obstructive pulmonary disease. Presse Med 2009, 38:406-412.

2. Mizutani N, Fuchikami J, Takahashi M, Nabe T, Yoshino S, Kohno S: Pulmonary emphysema induced by cigarette smoke solution and lipopolysaccharide in guinea pigs. Biol Pharm Bull 2009, 32:1559-1564.

3. Siganaki M, Koutsopoulos AV, Neofytou E, Vlachaki E, Psarrou M, Soulitzis N, Pentilas N, Schiza S, Siafakas NM, Tzortzaki EG: Deregulation of apoptosis mediators' p53 and bcl2 in lung tissue of COPD patients. Respir Res 2010, 11:46.
4. Hoffman AM, Ingenito EP: Alveolar epithelial stem and progenitor cells, emerging evidence for their role in lung regeneration. Curr Med Chem 2012, 19:6003-6008.

5. Whitsett JA, Wert SE, Weaver TE: Alveolar surfactant homeostasis and the pathogenesis of pulmonary disease. Annu Rev Med 2010, 61:105-119

6. Bonfield TL, Caplan Al: Adult mesenchymal stem cells, an innovative therapeutic for lung diseases. Discov Med 2010, 9:337-345.

7. Moodley Y, Manuelpillai U, Weiss DJ: Cellular therapies for lung disease, a distant horizon. Respirology 2011, 16:223-237.

8. Sinclair K, Yerkovich ST, Chambers DC: Mesenchymal stem cells and the lung. Respirology 2013, 18:397-411.

9. Giangreco A, Arwert EN, Rosewell IR, Snyder J, Watt FM, Stripp BR: Stem cells are dispensable for lung homeostasis but restore airways after injury. Proc Natl Acad Sci U S A 2009, 106:9286-9291.

10. Conese M, Carbone A, Castellani S, Di Gioia S: Paracrine effects and heterogeneity of marrow-derived stem/progenitor cells, relevance for the treatment of respiratory diseases. Cells Tissues Organs 2013, 197:445-473.

11. Gaur M, Ritner C, Sievers R, Pedersen A, Prasad M, Bernstein HS, Yeghiazarians Y: Timed inhibition of p38MAPK directs accelerated differentiation of human embryonic stem cells into cardiomyocytes. Cytotherapy 2010, 12:807-817.

12. Muguruma K, Sasai Y: In vitro recapitulation of neural development using embryonic stem cells, from neurogenesis to histogenesis. Dev Growth Differ 2012, 54:349-357.

13. Samadikuchaksaraei A, Bishop AE: Derivation and characterization of alveolar epithelial cells from murine embryonic stem cells in vitro. Methods Mol Biol 2006, 330:233-248.

14. Wang D, Haviland DL, Burns AR, Zsigmond E, Wetsel RA: A pure population of lung alveolar epithelial type II cells derived from human embryonic stem cells. Proc Natl Acad Sci U S A 2007, 104:4449-4454.

15. Gupta N, Su X, Popov B, Lee JW, Serikov V, Matthay MA: Intrapulmonary delivery of bone marrow-derived mesenchymal stem cells improves survival and attenuates endotoxin-induced acute lung injury in mice. J Immunol 2007, 179:1855-1863.

16. van Haaften $T$, Byrne R, Bonnet $S$, Rochefort GY, Akabutu J, Bouchentouf $M$, Rey-Parra GJ, Galipeau J, Haromy A, Eaton F, Chen M, Hashimoto K, Abley D, Korbutt G, Archer SL, Thébaud B: Airway delivery of mesenchymal stem cells prevents arrested alveolar growth in neonatal lung injury in rats. Am J Respir Crit Care Med 2009, 180:1131-1142.

17. Loi R, Beckett T, Goncz KK, Suratt BT, Weiss DJ: Limited restoration of cystic fibrosis lung epithelium in vivo with adult bone marrow-derived cells. Am J Respir Crit Care Med 2006, 173:171-179.

18. Sueblinvong V, Loi R, Eisenhauer PL, Bernstein IM, Suratt BT, Spees JL, Weiss DJ: Derivation of lung epithelium from human cord blood-derived mesenchymal stem cells. Am J Respir Crit Care Med 2008, 177:701-711.

19. Moodley Y, Atienza D, Manuelpillai U, Samuel CS, Tchongue J, llancheran S, Boyd R, Trounson A: Human umbilical cord mesenchymal stem cells reduce fibrosis of bleomycin-induced lung injury. Am J Pathol 2009, 175:303-313.

20. Zhen G, Xue Z, Zhao J, Gu N, Tang Z, Xu Y, Zhang Z: Mesenchymal stem cell transplantation increases expression of vascular endothelial growth factor in papain-induced emphysematous lungs and inhibits apoptosis of lung cells. Cytotherapy 2010, 12:605-614.

21. Huh JW, Kim SY, Lee JH, Lee JS, Van Ta Q, Kim M, Oh YM, Lee YS, Lee SD: Bone marrow cells repair cigarette smoke-induced emphysema in rats. Am J Physiol Lung Cell Mol Physiol 2011, 301:L255-L266.

22. Bonfield TL, Koloze M, Lennon DP, Zuchowski B, Yang SE, Caplan Al: Human mesenchymal stem cells suppress chronic airway inflammation in the murine ovalbumin asthma model. Am J Physiol Lung Cell Mol Physiol 2010, 299:L760-L770.

23. Goodwin M, Sueblinvong V, Eisenhauer P, Ziats NP, LeClair L, Poynter ME, Steele C, Rincon M, Weiss DJ: Bone marrow-derived mesenchymal stromal cells inhibit Th2-mediated allergic airways inflammation in mice. Stem Cells 2011, 29:1137-1148.

24. Lee SH, Jang AS, Kim YE, Cha JY, Kim TH, Jung S, Park SK, Lee YK, Won JH, Kim YH, Park CS: Modulation of cytokine and nitric oxide by mesenchymal stem cell transfer in lung injury/fibrosis. Respir Res 2010, 11:16.

25. Kim ES, Chang YS, Choi SJ, Kim JK, Yoo HS, Ahn SY, Sung DK, Kim SY, Park YR, Park WS: Intratracheal transplantation of human umbilical cord blood-derived mesenchymal stem cells attenuates Escherichia coli-induced acute lung injury in mice. Respir Res 2011, 12:108. 
26. Weiss DJ, Casaburi R, Flannery R, LeRoux-Williams M, Tashkin DP: A placebo-controlled, randomized trial of mesenchymal stem cells in COPD. Chest 2013, 143:1590-1598.

27. De Coppi P, Bartsch G Jr, Siddiqui MM, Xu T, Santos CC, Perin L, Mostoslavsky G, Serre AC, Snyder EY, Yoo JJ, Furth ME, Soker S, Atala A: Isolation of amniotic stem cell lines with potential for therapy. Nat Biotechnol 2007, 25:100-106.

28. Sun H, Feng K, Hu J, Soker S, Atala A, Ma PX: Osteogenic differentiation of human amniotic fluid-derived stem cells induced by bone morphogenetic protein-7 and enhanced by nanofibrous scaffolds. Biomaterials 2010 31:1133-1139.

29. Joo S, Ko IK, Atala A, Yoo JJ, Lee SJ: Amniotic fluid-derived stem cells in regenerative medicine research. Arch Pharm Res 2012, 35:271-280.

30. Hartmann K, Raabe O, Wenisch S, Arnhold S: Amniotic fluid derived stem cells give rise to neuron-like cells without a further differentiation potential into retina-like cells. Am J Stem Cells 2013, 2:108-118.

31. Sessarego N, Parodi A, Podestà M, Benvenuto F, Mogni M, Raviolo V, Lituania M, Kunkl A, Ferlazzo G, Bricarelli FD, Uccelli A, Frassoni F: Multipotent mesenchymal stromal cells from amniotic fluid, solid perspectives for clinical application. Haematologica 2008, 93:339-346.

32. Cananzi M, Atala A, De Coppi P: Stem cells derived from amniotic fluid, new potentials in regenerative medicine. Reprod Biomed Online 2009, 18:17-27.

33. Carraro G, Perin L, Sedrakyan S, Giuliani S, Tiozzo C, Lee J, Turcatel G, De Langhe SP, Driscoll B, Bellusci S, Minoo P, Atala A, De Filippo RE, Warburton $D$ : Human amniotic fluid stem cells can integrate and differentiate into epithelial lung lineages. Stem Cells 2008, 26:2902-2911.

34. Roubelakis MG, Trohatou O, Anagnou NP: Amniotic fluid and amniotic membrane stem cells, marker discovery. Stem Cells Int 2012, 2012:107836.

35. Li Y, Xu W, Yan J, Xia Y, Gu C, Ma Y, Tao H: Differentiation of human amniotic fluid-derived mesenchymal stem cells into type II alveolar epithelial cells in vitro. Int J Mol Med 2014, 33:1507-1513.

36. Pan HC, Cheng FC, Chen CJ, Lai SZ, Lee CW, Yang DY, Chang MH, Ho SP: Post-injury regeneration in rat sciatic nerve facilitated by neurotrophic factors secreted by amniotic fluid mesenchymal stem cells. J Clin Neurosci 2007, 14:1089-1098.

37. Zheng YB, Zhang XH, Huang ZL, Lin CS, Lai J, Gu YR, Lin BL, Xie DY, Xie SB, Peng L, Gao ZL: Amniotic-fluid-derived mesenchymal stem cells overexpressing interleukin-1 receptor antagonist improve fulminant hepatic failure. PLoS One 2012, 7:e41392.

38. Colosimo A, Russo V, Mauro A, Curini V, Marchisio M, Bernabò N, Alfonsi M, Mattioli M, Barboni B: Prolonged in vitro expansion partially affects phenotypic features and osteogenic potential of ovine amniotic fluid-derived mesenchymal stromal cells. Cytotherapy 2013, 15:930-950.

39. Zheng H, Liu Y, Huang T, Fang Z, Li G, He S: Development and characterization of a rat model of chronic obstructive pulmonary disease (COPD) induced by sidestream cigarette smoke. Toxicol Lett 2009, 189:225-234.

40. Jiang $H$, Zhu Y, Xu H, Sun Y, Li Q: Activation of hypoxia-inducible factor-1alpha via nuclear factor-kappa $B$ in rats with chronic obstructive pulmonary disease. Acta Biochim Biophys Sin (Shanghai) 2010, 42:483-488.

41. Agarwal AR, Yin F, Cadenas E: Short-term cigarette smoke exposure leads to metabolic alterations in lung alveolar cells. Am J Respir Cell Mol Biol 2014, 51:284-293.

42. Li YQ, Yan JP, Xu WL, Wang H, Xia YJ, Wang HJ, Zhu YY, Huang XJ: ADAM17 mediates MMP9 expression in lung epithelial cell. PLoS One 2013, 8:e51701.

43. Farkas L, Farkas D, Warburton D, Gauldie J, Shi W, Stampfli MR, Voelkel NF, Kolb M: Cigarette smoke exposure aggravates air space enlargement and alveolar cell apoptosis in Smad3 knockout mice. Am J Physiol Lung Cell Mol Physiol 2011, 301:L391-L401.

44. Macnee W: Pathogenesis of chronic obstructive pulmonary disease. Clin Chest Med 2007, 28:479-513.

45. Martin TR: Recognition of bacterial endotoxin in the lungs. Am J Respir Cell Mol Biol 2000, 23:128-132.

46. Sun D, Bu L, Liu C, Yin Z, Zhou X, Li X, Xiao A: Therapeutic effects of human amniotic fluid-derived stem cells on renal interstitial fibrosis in a murine model of unilateral ureteral obstruction. PLoS One 2013, 8:e65042.

47. Donovan PJ: High Oct-ane fuel powers the stem cell. Nat Genet 2001 29:246-247.

48. Pesce M, Gross MK, Schöler HR: In line with our ancestors, Oct- 4 and the mammalian germ. Bioessays 1998, 20:722-732.

49. Prusa AR, Marton E, Rosner M, Bernaschek $G$, Hengstschläger M Oct-4-expressing cells in human amniotic fluid, a new source for stem cell research? Hum Reprod 2003, 18:1489-1493.
50. Jomura S, Uy M, Mitchell K, Dallasen R, Bode CJ, Xu Y: Potential treatment of cerebral global ischemia with Oct-4+ umbilical cord matrix cells. Stem Cells 2007, 25:98-106.

51. Tondeur S, Assou S, Nadal L, Hamamah S, De Vos J: Biology and potential of human embryonic stem cells. Ann Biol Clin (Paris) 2008, 66:241-247.

52. Goldmann T, Kähler D, Schultz $H$, Abdullah M, Lang DS, Stellmacher F, Vollmer E: On the significance of Surfactant Protein-A within the human lungs. Diagn Pathol 2009, 4:8.

53. Fujino N, Kubo H, Suzuki T, Ota C, Hegab AE, He M, Suzuki S, Suzuki T, Yamada $\mathrm{M}$, Kondo $\mathrm{T}$, Kato H, Yamaya M: Isolation of alveolar epithelial type II progenitor cells from adult human lungs. Lab Invest 2011, 91:363-378.

54. Buckley S, Shi W, Carraro G, Sedrakyan S, Da Sacco S, Driscoll BA, Perin L, De Filippo RE, Warburton D: The milieu of damaged alveolar epithelial type 2 cells stimulates alveolar wound repair by endogenous and exogenous progenitors. Am J Respir Cell Mol Biol 2011, 45:1212-1221.

doi:10.1186/s12931-014-0120-3

Cite this article as: Li et al:: Therapeutic effects of amniotic fluid-derived mesenchymal stromal cells on lung injury in rats with emphysema.

Respiratory Research 2014 15:120.

\section{Submit your next manuscript to BioMed Central and take full advantage of:}

- Convenient online submission

- Thorough peer review

- No space constraints or color figure charges

- Immediate publication on acceptance

- Inclusion in PubMed, CAS, Scopus and Google Scholar

- Research which is freely available for redistribution

Submit your manuscript at www.biomedcentral.com/submit
C Biomed Central 